\title{
Demonstrating new understandings of the development of the Asian Tethyan Realm: Fourth International Symposium of IGCP-589 and field excursion in Thailand
}

\author{
Xiaochi Jin ${ }^{1}$, Thasinee Charoentitirat ${ }^{2}$ \\ ${ }^{1}$ Institute of Geology, Chinese Academy of Geological Sciences, 26 Baiwanzhuang Road, Beijing 100037, China. E-mail: jinxchi@cags.ac.cn; \\ jinxchi@sina.com, Website: http://igcp589.cags.ac.cn/ \\ ${ }^{2}$ Department of Geology, Faculty of Science, Chulalongkorn University, Bangkok, Thailand
}

IGCP Project 589 (Development of the Asian Tethyan Realm: Genesis, Process and Outcomes) held its fourth international symposium on October 26-27, 2015 in the campus of Chulalongkorn University in Bangkok, Thailand. A five-day (Oct. 28- Nov. 1) postsymposium field excursion was conducted in the Lampang-Chiang Mai area in northern Thailand. Thanks to the commitment of colleagues of the Department of Geology, Chulalongkorn University and vigorous support of IUGS and UNESCO, both the symposium and field trip were fruitful and well acknowledged by participants.

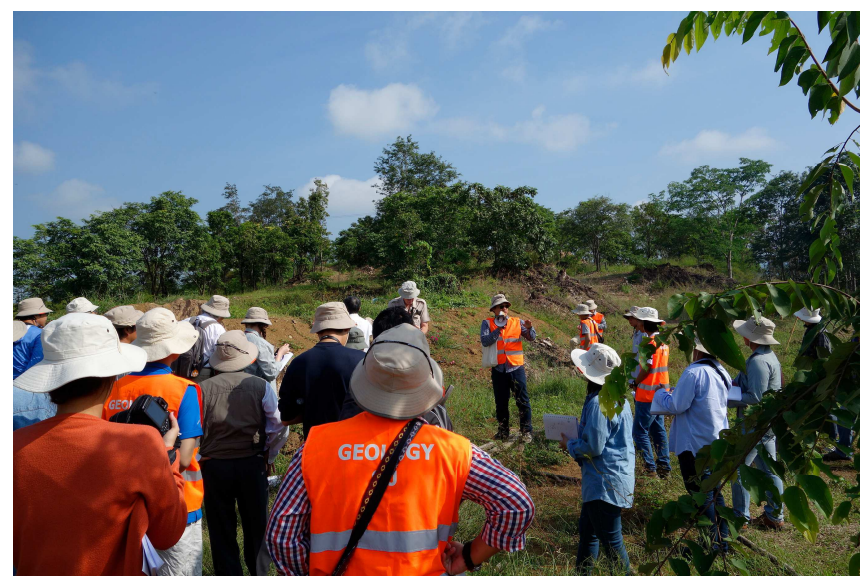

Figure 1. Participants of post-symposium field excursion at an outcrop of a sandstone-dominated clastic succession about $8 \mathrm{~km}$ southeast of Lamphun in northern Thailand. The age of the sandstone is considered to be Permian based on regional stratigraphic correlation.

More than 40 participants from Australia, Belgium, China, Japan, Malaysia, Myanmar, Philippines, Thailand, Turkey, UK, and Vietnam took parts in the symposium and exchanged their latest understandings of the development of the Tethys. 27 oral and 16 poster presentations were given addressing problems of tectonic configuration, regional geology, biostratigraphy, paleogeogrphic evolution, geochemistry, petrology, and mineral resources exploration related to the development of the Asian Tethyan Realm. 3 keynote speakers devoted efforts respectively on 1) the evolution of the Khao Khwang Fold and Thrust Belt, 2) fluid evolution through di-fferent deformation stages, and 3) multidisciplinary constraints on the Sukhothai and Loei
Belts. It is encouraging that many students from different countries took parts in the symposium. Also a large number of the students of the Department of Geology, Chulalongkorn attended the meeting. They functioned as hosts, staff members and participants.

Thailand has been an active participant of IGCP projects and has the tradition of hosting international geological studies in its territory. These advantages make Thailand an ideal place to hold this year's symposium. Reciprocally, this event effectively promoted the activities of geological investigations in Thailand and inspired the enthusiasm of local geologists and students.

Northern Thailand is a geologically very complicated region that accommodates the complexes of eastern Paleo-Tethyan suture(s). The five-day post-symposium field excursion took place in the LampangChiang Mai area where the participants were able to observe various rocks representing the Sibumasu block and the Sukhothai zone. The focus of the trip was on tectonic evolution of the early Mesozoic collision between the Sibumasu block and the Indochina block/ Sukhothai Zone. The Cenozoic basins in northern Thailand were also a target of the trip. Moreover, participants were allowed to visit some local attractions e.g. the Thailand's biggest coal mine, the Golden Temple of Doi Suthep, and the Sankampaeng Hot Spring.

The IGCP project 589 is led by Xiaochi JIN (China), Katsumi UENO (Japan), Graciano YUMUL JR. (Philippines), and Pol CHAODUMRONG (Thailand). The project started in 2012 and held its inaugural international symposium in Xi' an, China with a field excursion in the Qinling Orogen in central China; the second international symposium in 2013 in Boracay Island, Philippines with a field excursion in Panay Island of Philippines; and the third in 2014 in Teheran, Iran with a field excursion in the Alborz Mountains and another excursion in the central Iran blocks and the Sanandaj-Sirjan zone.

As a major component of mainland SE Asia and a geologically significant region in the Tethyside, Myanmar has been drawing increasingly the attention of geologists who are interested in the development of Asian Tethyan Realm. It was decided at the business meeting of the project that the fifth international symposium of IGCP589 be held in Yangon, Myanmar in the period of late October to early November, 2016. A two-day pre-symposium trip to the western Arakhan and a five-day post-symposium excursion in western Shan State are planned. See you in Myanmar in 2016. 